\title{
The Outcome of Endoscopic Radiofrequency Anti-Reflux Therapy (STRETTA) for Gastroesophageal Reflux Disease in Patients with Previous Gastric Surgery: A Prospective Cohort Study
}

\author{
Edward John Nevins, James Edward Dixon and Yirupaiahgari Krishnaiah Setty Viswanath \\ Department of Upper GI surgery, James Cook University Hospital, South Tees Hospitals NHS Foundation Trust, Middlesbrough, UK
}

Background/Aims: STRETTA improves the quality of life and reduces the need for anti-reflux medication in select patients, especially those with uncomplicated gastroesophageal reflux disease (GERD). We aimed to review the outcomes of STRETTA in patients with medically refractory GERD, who had undergone previous gastric surgery.

Methods: This was a review of a prospective database in a British center. Since 2016, all GERD patients who underwent STRETTA and had a history of previous gastric surgery were studied $(n=11)$. Anti-reflux medication pre- and post-STRETTA was evaluated. The outcomes were assessed objectively by the change in anti-reflux medication and subjectively through a pre- and post-procedure GERD-health-related quality of life (HRQL) questionnaire.

Results: The median length of follow-up was 23 months. Nine patients demonstrated improved GERD-HRQL scores following STRETTA (82\%). Of the 7 patients who underwent fundoplication, all reported improved symptoms, with 3 patients discontinuing the medication and 3 patients on a reduced dose of proton pump inhibitor. Four patients underwent surgery other than fundoplication, of which 2 reported improvement and discontinued the proton pump inhibitor. Two patients reported no improvement.

Conclusions: This study demonstrates that STRETTA is successful in reducing refractory GERD in patients with previous gastric surgery. The outcomes were comparable to published outcomes in patients with uncomplicated GERD with no previous history of gastric surgery. Clin Endosc 2021;54:542-547

Key Words: Endoscopic management; Gastro-esophageal reflux disease; Revisional anti-reflux procedure; STRETTA

\section{INTRODUCTION}

Endoscopic radiofrequency therapy for gastroesophageal reflux disease (GERD) has been proven to be successful. ${ }^{1}$ STRETTA is the only radiofrequency device licensed for this indication in the UK and is approved by The National Institute

Received: September 4, 2020 Revised: November 25, 2020

Accepted: November 30, 2020

Correspondence: James Edward Dixon

Department of Upper GI Surgery, South Tees Hospitals NHS Foundation Trust, James Cook University Hospital, Marton Road, Middlesbrough, Cleveland TS4 3BW, UK

Tel: +44-16-4285-0850, E-mail: james.dixon5@nhs.net

ORCID: https://orcid.org/0000-0001-7860-710X

cc This is an Open Access article distributed under the terms of the Creative Commons Attribution Non-Commercial License (http://creativecommons.org/ licenses/by-nc/3.0) which permits unrestricted non-commercial use, distribution, and reproduction in any medium, provided the original work is properly cited. for Health and Care Excellence (NICE) for cases refractory to medical therapy. ${ }^{2}$

STRETTA improves the quality of life and reduces the need for anti-reflux medication in a select group of patients, ${ }^{3}$ namely those with uncomplicated GERD. Complicated GERD is defined as the presence of stenotic disease, ulcerative esophagitis, scarring of the gastro-esophageal junction (GEJ), a recurrent hiatus hernia of $>2.5 \mathrm{~cm}$, a dilated crura of $>2.5 \mathrm{~cm}$, Barrett's metaplasia, wrap migration, and gastric volvulus. ${ }^{4}$ At our center, STRETTA is not performed on patients with complicated GERD. STRETTA has also been shown to be cost-effective in some studies. ${ }^{5}$

For refractory GERD in patients with a history of previous gastric surgery, STRETTA is effective; however, it has been reported only in a few studies. A retrospective study of 6 patients with a history of previous Roux-en-Y gastric bypass showed that STRETTA led to resolution of the symptoms in 
5 patients. ${ }^{6}$ Two prospective studies with a small sample size that reviewed STRETTA following anti-reflux surgery demonstrated good outcomes in patients with treatment-refractory GERD; 15/18 patients had improved outcomes, ${ }^{7}$ and 6/7 patients were satisfied with the results. ${ }^{8}$

We aimed to review the outcomes of STRETTA at a specialist center in patients who had undergone previous gastric surgery and had GERD refractory to medication. This case series will add to the limited evidence for the use of STRETTA in patients with a history of gastric surgery, having GERD refractory to medication.

\section{MATERIALS AND METHODS}

This was a review of a prospectively maintained database at a tertiary referral center in the UK. In all, 196 patients underwent STRETTA since 2016. Of these, 11 patients who had undergone previous gastric surgery were identified. All patients were assessed by pre-operative endoscopy, 24-hour $\mathrm{pH}$ and manometry, and barium studies. Demographic data such as age, sex, and history of previous surgery were recorded in a prospectively maintained database. Anti-reflux medication before and after STRETTA were reviewed. The reported outcome of STRETTA was assessed objectively by the change in anti-reflux medication post-procedure and subjectively through a pre- and post-procedure questionnaire. The questionnaire used was the GERD-health-related quality of life (GERD-HRQL), which has been validated for assessing the severity of GERD. ${ }^{9}$ The pre-procedure GERD-HRQL was administered at the pre-procedure clinic appointment.
Due to the waiting period in the National Health Service, the time from this appointment to the actual procedure was variable. However, all patients were screened on the day of the procedure to confirm that the ongoing symptoms persisted. The post-procedure GERD-HRQL was administered at the post-procedure follow-up appointment, between 4 and 12 weeks after the procedure. The overall length of follow-up was determined by the time since the procedure as the medications post-procedure were reviewed on the same date, April 29, 2020 (follow-up range, 2-42 months). A local ethics committee approved the maintenance of the prospective database, and patients provided written consent for the treatment and study.

The indications for STRETTA in our center are in conformity with the NICE guideline according to which, if proton pump inhibitor (PPI) medication has failed to resolve the symptoms, endoscopic radiofrequency therapy may be used before or after the surgery. ${ }^{3}$

\section{RESULTS}

Eleven patients were included in the case series. The median follow-up duration was 23 months (range, 2-42 months). Nine patients demonstrated improved GERD-HRQL scores following STRETTA (82\%) (Fig. 1). Of these, 3 patients required no further anti-reflux medication. Before STRETTA, all 11 patients were taking a PPI. After the procedure, 5 of them were able to discontinue the PPI altogether, and 3 patients had a reduced dose of PPI.

Fundoplication was the most common intervention (Table 1). Of the 7 patients who had undergone a previous fundo-

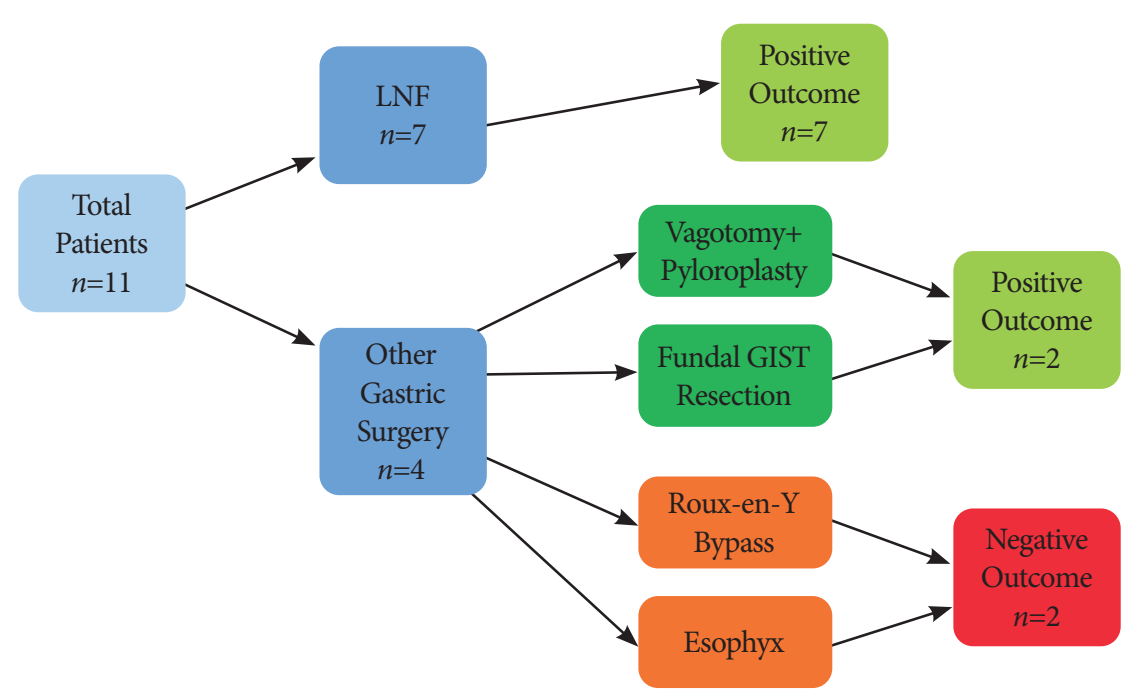

Fig. 1. Flowchart of the outcomes following STRETTA. GIST, gastrointestinal stromal tumor; LNF, laparoscopic Nissen fundoplication. 
plication, all reported an improvement in symptoms (100\%), with 3 patients discontinuing the medication completely (43\%) and 3 patients on a reduced dose of PPI (43\%). Only 1 patient with a history of fundoplication did not discontinue or reduce the PPI usage following STRETTA; however, the H2-receptor antagonist (H2RA) was no longer required. Endoscopic images before and after the procedure of a patient with a history of previous fundoplication are demonstrated in Figs. 2A and 2B.

Four patients underwent gastric interventions other than fundoplication (Table 2). Two of these patients reported an improvement (50\%). Of these, 1 patient with a history of vagotomy and pyloroplasty discontinued the PPI altogether, and is now only on an antacid. The other patient, with a history of resection for a fundal gastrointestinal stromal tumor (GIST), reported an excellent outcome, with a significant improvement in symptoms. The endoscopic images of these patients are shown in Figs. 2C and 2D.

One patient, with a history of an Esophyx or transoral incisionless fundoplication (TIF), was only on PPI before STRETTA; however, following the procedure is on PPI and an antacid. The endoscopic images of this patient are shown in Fig. 2E, F. This patient underwent 2 additional revisional anti-reflux surgeries after EsophyX. Biopsies showed benign esophageal inflammatory changes without Barrett's esophagus.

A patient with a history of gastric bypass, who showed no improvement on the subjective scoring system, now requires only a PPI on a PRN (pro re nata) basis, although he required regular PPI and antacids before the procedure.

The time from original gastric surgery to STRETTA varied from 2 years to 40 years. There was no link between the time since surgery and outcomes following STRETTA.

Table 1. Patients Who Had Undergone Previous Fundoplication and Their Results following STRETTA

\begin{tabular}{cccccccc}
\hline Patient & $\begin{array}{c}\text { Date of } \\
\text { STRETTA }\end{array}$ & Age & Sex & $\begin{array}{c}\text { Follow-up } \\
(\mathbf{m o})\end{array}$ & Pre STRETTA meds & Post STRETTA meds & $\begin{array}{c}\text { Reported } \\
\text { outcome }\end{array}$ \\
\hline 1 & 2016 & 57 & M & 42 & PPI + Antacid & Reduced PPI dose, antacid stopped & Improved \\
2 & 2016 & 66 & F & 40 & PPI & No medication dependence & Improved \\
3 & 2017 & 66 & M & 39 & PPI & Reduced PPI dose & Improved \\
4 & 2018 & 44 & M & 23 & PPI + Antacid + H2RA & Reduced PPI dose, antacid and H2RA stopped & Improved \\
5 & 2018 & 66 & F & 16 & PPI + Antacid & No medication dependence & Improved \\
6 & 2019 & 62 & F & 7 & PPI + Antacid + H2RA & No medication dependence & Improved \\
7 & 2020 & 54 & F & 4 & PPI + Antacid + H2RA & PPI and Antacid the same, H2RA stopped & Slightly improved \\
\hline
\end{tabular}

H2RA, H2-receptor antagonist; PPI, proton pump inhibitor.

Table 2. Patients with a History of Previous Gastric Surgery Other than Fundoplication and Their Results following STRETTA

\begin{tabular}{|c|c|c|c|c|c|c|c|c|}
\hline Patient & Previous surgery & $\begin{array}{c}\text { Date of } \\
\text { STRETTA }\end{array}$ & Age & Sex & $\begin{array}{l}\text { Follow up } \\
\quad(\mathrm{mo})\end{array}$ & $\begin{array}{l}\text { Pre STRETTA } \\
\text { meds }\end{array}$ & Post STRETTA meds & $\begin{array}{l}\text { Reported } \\
\text { outcome }\end{array}$ \\
\hline 1 & $\begin{array}{l}\text { Esophyx and two further } \\
\text { revisional antireflux surgeries }\end{array}$ & 2017 & 64 & M & 30 & PPI & $\begin{array}{l}\text { Ongoing PPI usage with } \\
\text { antacid }\end{array}$ & $\begin{array}{l}\text { No Improve- } \\
\text { ment }\end{array}$ \\
\hline 2 & Fundal GIST resection & 2017 & 68 & $\mathrm{~F}$ & 30 & PPI + Antacid & $\begin{array}{c}\text { PPI stopped } \\
\text { Now taking H2RA + antacid }\end{array}$ & Improved \\
\hline 3 & Roux-en-Y gastric bypass & 2018 & 70 & $\mathrm{~F}$ & 16 & PPI + Antacid & $\begin{array}{l}\text { Ongoing PPI, antacid } \\
\text { stopped }\end{array}$ & $\begin{array}{c}\text { No improve- } \\
\text { ment }\end{array}$ \\
\hline 4 & Vagotomy and pyloroplasty & 2018 & 67 & M & 16 & PPI + Antacid & $\begin{array}{c}\text { PPI stopped } \\
\text { Ongoing antacid }\end{array}$ & Improved \\
\hline
\end{tabular}

GIST, gastrointestinal stromal tumor; H2RA, H2-receptor antagonist; PPI, proton pump inhibitor. 
Nevins EJ et al. STRETTA for Reflux Following Gastric Surgery

\begin{tabular}{|c|c|c|}
\hline Procedure & Pre-STRETTA endoscopic appearance & Post-STRETTA endoscopic appearance \\
\hline $\begin{array}{l}\text { Previous } \\
\text { fundoplication }\end{array}$ & $\begin{array}{l}\text { Loose wrap with the preserved angle of His, } \\
\text { and a lax GEJ, with refluxing gastric } \\
\text { contents (arrow) }\end{array}$ & $\begin{array}{l}\text { B } \\
\text { Spherical thermal lesions following } \\
\text { STRETTA (arrow) }\end{array}$ \\
\hline $\begin{array}{l}\text { Resection of } \\
\text { Fundal GIST } \\
\text { with fundus } \\
\text { scarring }\end{array}$ & Fundal scar (arrow) & $\begin{array}{l}\text { Spherical thermal lesions following } \\
\text { STRETTA (arrow) }\end{array}$ \\
\hline $\begin{array}{l}\text { Esophyx and } \\
\text { two further } \\
\text { revisional } \\
\text { antireflux } \\
\text { surgeries }\end{array}$ & $\begin{array}{l}\text { Esophyx fastener at GEJ (arrow), } \\
\text { maintained angle of His, with laxity of GEJ, } \\
\text { and prolapse of the gastric mucosa }\end{array}$ & $\begin{array}{l}\text { Ongoing prolapse of gastric mucosa, which } \\
\text { may explain the patients' failure to improve. } \\
\text { Spherical thermal lesions (arrow) }\end{array}$ \\
\hline
\end{tabular}

Fig. 2. Endoscopic images pre- and post-STRETTA. GEJ, gastro-esophageal junction; GIST, gastrointestinal stromal tumor. 


\section{DISCUSSION}

Symptoms of GERD are common in patients who have undergone previous gastric surgery. This might be due to non-resolution of the symptoms following an attempt at anti-reflux surgery or as a direct result of the procedure itself, such as in Roux-en-Y gastric bypass. ${ }^{6}$ In patients with no history of previous gastric surgery, STRETTA has shown a reduction in the dependence on PPI. However, in most patients, PPI cannot be completely discontinued. ${ }^{10}$ Considering PPI usage as a measure of success of STRETTA, only $73 \%$ of the patients in this series could discontinue or reduce PPI. A previous study that evaluated STRETTA in patients with no previous gastric surgery reported that $78 \%$ of patients could discontinue or reduce PPI. ${ }^{10}$ This suggests that patients who have undergone previous gastric interventions might have outcomes comparable to those who did not.

Laparoscopic Nissen fundoplication (LNF) has been considered as the gold standard intervention for GERD resistant to optimal medical therapy. However, it has been reported that $21 \%$ of the patients after LNF will have ongoing GERD symptoms requiring medication, and $17 \%$ will require revisional surgery. ${ }^{11}$ These patients face the prospect of lifelong dependence on medication or a second surgery. Revisional Nissen fundoplication is associated with a lower probability of success and a greater risk of morbidity. ${ }^{7}$ Alternatively, longterm anti-reflux medication usage is associated with a high cost and long-term risks such as infectious complications, cardiac complications, and nutritional problems. ${ }^{12}$ STRETTA is proven to be more cost-effective than surgical management. ${ }^{13}$ A study involving 7 patients with persistent reflux after anti-reflux surgery, showing that $85.7 \%$ of the patients were satisfied with the result following STRETTA. ${ }^{8}$ In the present case series, similar results were achieved. $100 \%$ of the patients who underwent fundoplication could discontinue or reduce the PPI medication following STRETTA. Overall, patients with failed previous Nissen fundoplication are likely to have a significant benefit from STRETTA as they can potentially reduce or discontinue PPI medications and can avoid a revisional surgery, which has a higher risk. We have demonstrated good outcomes in patients who have undergone previous fundoplication, and therefore STRETTA might augment the neo-GEJ following fundoplication.

Clinicians should remember changes in the gastric anatomy, and therefore physiology following gastric surgery might be the reason for the failure of STRETTA in these patients. For example, in patients who have undergone Roux-en-Y gastric bypass or pyloroplasty, GERD symptoms are likely to be due to bile reflux following changes in the anatomy of the distal stomach. Furthermore, the formation of the gastric tube during a gastric bypass obliterates the angle of His, which normally prevents reflux of bile into the esophagus. ${ }^{6}$ Although STRETTA is postulated to stimulate muscular hypertrophy, increasing the tone of the lower esophageal sphincter, it does not affect the angle of His. In the present study, we had a single patient with persistent symptoms following STRETTA after Roux-en-Y gastric bypass, although the medication requirements had decreased. However, in a study on outcomes of STRETTA following laparoscopic Roux-en-Y gastric bypass, $83 \%$ of the patients had complete resolution of symptoms. The sample size was small $(n=6)$; however, the patients were followed up for a mean of 20 months, by which time 5 patients were asymptomastic. ${ }^{6}$ Further research on STRETTA following gastric bypass surgery is necessary with larger sample size.

Only one patient in our data set had undergone a previous TIF or EsophyX, a novel alternative anti-reflux endoscopic procedure. The patient reported no improvement and required additional anti-reflux medication post-procedure. EsophyX is effective in managing GERD. In a study that followed patients for 6 years following EsophyX, 86\% of the patients required a reduced dose of PPI, and around 50\% of them had discontinued the PPI completely. ${ }^{14}$ In TIF, the stomach, and distal esophagus are pulled together into a roll to form a valve at the lower esophageal sphincter, held in place by multiple polypropylene fasteners. ${ }^{15}$ These fasteners might disrupt the delivery of energy during STRETTA, which might be responsible for the failure of STRETTA in this patient.

The small sample size is a limitation of this case series. Nevertheless, though STRETTA is not routinely used for recurrent or primary GERD after gastric surgery, we believe this is the second-largest cohort of patients on this topic. ${ }^{7}$ An additional limitation is the lack of post-operative $\mathrm{pH}$ or manometry studies to help establish reasons for the success or failure of the STRETTA procedure. These tests are not routinely performed postoperatively at our center. This is an initial study that demonstrates that STRETTA is safe and likely to be beneficial in this cohort; however, further research is necessary to predict treatment success. This includes correlation with additional measures for GERD-HRQL, such as symptom index or symptom association probability. ${ }^{16}$

In summary, this case series demonstrates that STRETTA is successful in reducing refractory GERD in patients with a history of gastric surgery. The outcomes in this cohort of patients were comparable to published outcomes in patients with uncomplicated GERD who have not previously undergone a gastric intervention.

Conflicts of Interest

The authors have no potential conflicts of interest. 
Funding

None.

Author Contributions

Conceptualization: Edward John Nevins, Yirupaiahgari Krishnaiah Setty Viswanath

Supervision: YKSV

Writing-original draft: James Edward Dixon

Writing-review\&editing: EJN, JED, YKSV

\section{ORCID}

Edward John Nevins:

https://orcid.org/0000-0002-4172-3729

James Edward Dixon:

https://orcid.org/0000-0001-7860-710X

Yirupaiahgari Krishnaiah Setty Viswanath: https://orcid.org/0000-0003-3880-1172

\section{REFERENCES}

1. He S, Xu F, Xiong X, et al. Stretta procedure versus proton pump inhibitors for the treatment of nonerosive reflux disease: a 6-month follow-up. Medicine (Baltimore) 2020;99:e18610.

2. National Institute for Health and Care Excellence. Stretta system for gastro-oesophageal reflux disease [Internet]. London: NICE; c2016 [updated 2016 Jul 26]. Available from: https://www.nice.org.uk/advice/mib74.

3. Viswanath Y, Maguire N, Obuobi RB, Dhar A, Punnoose S. Endoscopic day case antireflux radiofrequency (Stretta) therapy improves quality of life and reduce proton pump inhibitor (PPI) dependency in patients with gastro-oesophageal reflux disease: a prospective study from a UK tertiary centre. Frontline Gastroenterol 2019;10:113-119.

4. Viswanath YKS. Endoscopic prudence to assess gastro-esophageal junction (GEJ); a necessity rather a prerequisite prior to endoscopic anti-reflux treatment in gastro-esophageal reflux disease (GERD) patients. Acta Scientific Gastrointestinal Disorders 2020;3:29-31.

5. Funk LM, Zhang JY, Drosdeck JM, Melvin WS, Walker JP, Perry KA.
Long-term cost-effectiveness of medical, endoscopic and surgical management of gastroesophageal reflux disease. Surgery 2015;157:126-136.

6. Mattar SG, Qureshi F, Taylor D, Schauer PR. Treatment of refractory gastroesophageal reflux disease with radiofrequency energy (Stretta) in patients after Roux-en-Y gastric bypass. Surg Endosc 2006;20:850-854.

7. Noar M, Squires $P$, Khan S. Radiofrequency energy delivery to the lower esophageal sphincter improves gastroesophageal reflux patient-reported outcomes in failed laparoscopic Nissen fundoplication cohort. Surg Endosc 2017;31:2854-2862.

8. McClusky DA, 3rd, Khaitan L, Swafford VA, Smith CD. Radiofrequency energy delivery to the lower esophageal sphincter (Stretta procedure) in patients with recurrent reflux after antireflux surgery: can surgery be avoided? Surg Endosc 2007;21:1207-1211.

9. Velanovich V. The development of the GERD-HRQL symptom severity instrument. Dis Esophagus 2007;20:130-134.

10. Coron E, Sebille V, Cadiot G, et al. Clinical trial: radiofrequency energy delivery in proton pump inhibitor-dependent gastro-oesophageal reflux disease patients. Aliment Pharmacol Ther 2008;28:1147-1158.

11. Kelly JJ, Watson DI, Chin KF, Devitt PG, Game PA, Jamieson GG. Laparoscopic Nissen fundoplication: clinical outcomes at 10 years. J Am Coll Surg 2007;205:570-575

12. Shah NH, LePendu P, Bauer-Mehren A, et al. Proton pump inhibitor usage and the risk of myocardial infarction in the general population. PLoS One 2015;10:e0124653.

13. Gregory D, Scotti DJ, Buck D, Triadafilopoulos G. Budget impact analysis to estimate the cost dynamics of treating refractory gastroesophageal reflux disease with radiofrequency energy: a payer perspective. Manag Care 2016;25:42-50.

14. Testoni PA, Testoni S, Mazzoleni G, Vailati C, Passaretti S. Long-term efficacy of transoral incisionless fundoplication with Esophyx (Tif 2.0) and factors affecting outcomes in GERD patients followed for up to 6 years: a prospective single-center study. Surg Endosc 2015;29:2770-2780.

15. Testoni PA, Mazzoleni G, Testoni SG. Transoral incisionless fundoplication for gastro-esophageal reflux disease: Techniques and outcomes. World J Gastrointest Pharmacol Ther 2016;7:179-189.

16. Vaezi MF. Use of symptom indices in the management of GERD. Gastroenterol Hepatol (N Y) 2012;8:185-187. 